\title{
Correction to: The Molecular Mechanism of Aluminum Phosphide poisoning in Cardiovascular Disease: Pathophysiology and Diagnostic Approach
}

\author{
Seyed Farzad Hosseini ${ }^{1} \cdot$ Mehdi Forouzesh $^{2} \cdot$ Mohsen Maleknia $^{3,4} \cdot$ Samira Valiyari $^{2} \cdot$ Mahmood Maniati $^{5}$. \\ Azin Samimi ${ }^{1,6}$
}

Published online: 3 September 2020

(c) Springer Science+Business Media, LLC, part of Springer Nature 2020

\section{Correction to: Cardiovascular Toxicology https://doi.org/10.1007/s12012-020-09592-4}

The article "The Molecular Mechanism of Aluminum Phosphide poisoning in Cardiovascular Disease: Pathophysiology and Diagnostic Approach", written by Seyed Farzad Hosseini · Mehdi Forouzesh · Mohsen Maleknia · Samira Valiyari · Mahmood Maniati · Azin Samimi, was originally published electronically on the publisher's internet portal (currently SpringerLink) on 25th July 2020 with open access. With the author(s)' decision to step back from Open Choice, the copyright of the article changed on 29th July 2020 to (C) Springer Science+Business Media, LLC, part of Springer Nature 2020 and the article is forthwith distributed under the terms of copyright.

The original article has been corrected.

Publisher's Note Springer Nature remains neutral with regard to jurisdictional claims in published maps and institutional affiliations.

The original article can be found online at https://doi.org/10.1007/ s12012-020-09592-4.

Azin Samimi

Azin.samimi831@gmail.com

1 Legal Medicine Research Center, Legal Medicine

Organization, Ahvaz, Iran

2 Legal Medicine Research Center, Legal Medicine Organization, Tehran, Iran

3 Thalassemia \& Hemoglobinopathy Research Center, Health Research Institute, Ahvaz Jundishapur University of Medical Sciences, Ahvaz, Iran

4 Student Research Committee, Ahvaz Jundishapur University of Medical Sciences, Ahvaz, Iran

5 Ahwaz Jundishapur University of Medical Sciences, Ahwaz, Iran

6 Department of Toxicology, Faculty of Pharmacy, Ahvaz Jundishapur University of Medical Sciences, Ahvaz, Iran 